Bioconjug Chem. 2016 May 18; 27(5): 1411-1418. doi:10.1021/acs.bioconjchem.6b00181.

\title{
Reactivity, Selectivity and Stability in Sulfenic Acid Detection: A Comparative Study of Nucleophilic and Electrophilic Probes
}

\author{
Vinayak Gupta, Hanumantharao Paritala, and Kate S. Carroll ${ }^{\star}$
}

\begin{abstract}
The comparative reaction efficiencies of currently used nucleophilic and electrophilic probes towards cysteine sulfenic acid have been thoroughly evaluated in two different settings - (i) a small molecule dipeptide based model and, (ii) a recombinant protein model. We further evaluated the stability of corresponding thioether and sulfoxide adducts under reducing conditions which are commonly encountered during proteomic protocols and in cell analysis. Powered by the development of new cyclic and linear C-nucleophiles, the unsurpassed efficiency in the capture of sulfenic acid under competitive conditions is achieved and thus holds great promise as highly potent tools for activity-based sulfenome profiling.
\end{abstract}

\section{Graphical Abstract}

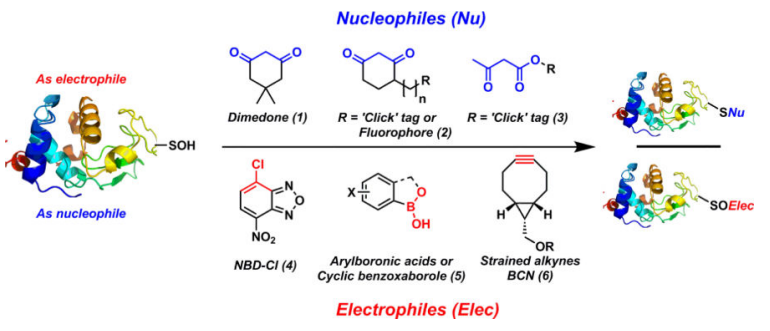

\section{Introduction}

Owing to the intrinsic nucleophilicity and oxidation susceptibility, cysteine thiols (Cys-SH) are prime targets for the redox-based modulation of protein activity. Oxidation of a protein cysteine thiol (Cys-SH) to sulfenic acid (Cys-SOH) by reactive oxygen species (ROS) (e.g. $\mathrm{H}_{2} \mathrm{O}_{2}$ ), termed $S$-sulfenylation, is a reversible post-translational modification that plays a crucial role in regulating several protein functions. ${ }^{1-6}$ With an estimated half-life in minutes, Cys-SOH is considered a transient species whose ultimate fate depends upon factors such as presence of neighbouring thiol, level/duration of ROS and protein microenvironment. ${ }^{5}$ Essentially, absence of proximal thiols capable of forming intramolecular disulfide bond, limited solvent access and proximal hydrogen bond acceptors contribute towards $\mathrm{Cys}-\mathrm{SOH}$

\footnotetext{
*Corresponding Author; Email: kcarroll@scripps.edu ASSOCIATED CONTENT

The Supporting Information is available free of charge on the ACS Publications website at DOI: Experimental procedures, ${ }^{1} \mathrm{H}$ NMR, ${ }^{13}$ C NMR, and LC-MS data including stability studies.

The authors declare no competing financial interest.
} 
stabilization. High/chronic oxidative stress may cause - $\mathrm{SOH}$ to undergo further oxidation to irreversible sulfinic $\left(\mathrm{Cys}-\mathrm{SO}_{2} \mathrm{H}\right)$ or sulfonic acid $\left(\mathrm{Cys}-\mathrm{SO}_{3} \mathrm{H}\right)$. Due to the abundance of biological thiols (mM levels), an important and facile biological reaction of $\mathrm{Cys}-\mathrm{SOH}$ is the disulfide formation. The nascent disulfide may undergo thiol-disulfide exchange to regenerate initial Cys-SH. Cys-SOH may undergo intramolecular reaction with adjacent amide nitrogen resulting in the formation of a cyclic species known as cyclic sulfenamide which may be reduced back to thiol via disulfide formation. Due to the central role of Cys$\mathrm{SOH}$ in reversible/irreversible pathway, it serves as an important hub within the redox milieu. ${ }^{5}$ Indeed, over the past decade several groups have reported the role of Cys-SOH in regulation of several proteins such as transcription factors, kinases, phosphatases, ion channels, peroxidases and cysteine proteases, sirtuins, human serum albumin and many others. ${ }^{3,}{ }^{6} 21$ Moreover, aberrant Cys-SOH formation has been shown to correlate with disease state. ${ }^{12}{ }^{22}$ The aforementioned examples and many other reports establish protein $S$ sulfenylation as a global signaling mechanism akin to phosphorylation and a potential drug target. ${ }^{5}, 6,15,23 \_27$

Due to the electrophilic as well as nucleophilic character of sulfur atom in Cys-SOH, the detection methods exploiting both have been reported (Fig. 1). ${ }^{5}, 10 \_13,19,20,25,26,28-43$ Briefly, due to higher electrophilicity (than nucleophilicity) of Cys-SOH, vast majority of probes are nucleophilic in nature and based on cyclic 1,3-carbonyl scaffold such as dimedone (1). These nucleophilic probes reacts with Cys-SOH to give thioether adducts. Such nucleophilic probes are extensively employed to study qualitative and quantitative capture of Cys-SOH. , ${ }^{1},{ }^{9}-11,13 \_16,18 \_22,29 \_32,34 \_39,42 \_51$ Commonly used repertoire of Cnucleophilic probes consist of commercially available 1,3-dicarbonyl-based 'clickable' probes such as DYn-2 (2a), ${ }^{15}$ DAz-2 (2b), ${ }^{10}$ Alk- $\beta$-KE (3), ${ }^{46}$ BP1 (7), ${ }^{44}$ and under development 6-hydroxy derivatives of phenalene-1,3-dione (8) (Fig. 2). Enrichment-ready/ imaging-ready reagents such as DCP-Bio1 (2c) and DCP-Rho1 (2d) have also been made commercially available and used extensively. ${ }^{30}$ Although these nucleophilic probes are selective for protein sulfenic acid under aqueous physiological conditions, they suffer from poor reaction kinetics $\left(k_{\text {obs }}=0.008 \mathrm{M}^{-1} \mathrm{~s}^{-1}-0.05 \mathrm{M}^{-1} \mathrm{~s}^{-1}\right)$ when compared to other biological reactions of Cys-SOH (such as disulfide formation or over-oxidation to sulfinic/ sulfonic acid). ${ }^{5}$ To overcome this limited reactivity problem, we recently developed and reported a facile mass-spectrometery-based assay and a repurposed dipeptide-based sulfenic acid model using which we screened a library of cyclic and linear $C$-nucleophiles for reactivity towards sulfenic acid under aqueous conditions. We obtained the reaction rate constants of more than $150 \mathrm{C}$-nucleophiles and from this collection we identified novel classes of compounds with more than 200-fold enhanced reactivity towards Cys-SOH. ${ }^{25},{ }^{26}$

Sulfenic acid can also act as a nucleophile and react with electrophiles to produce a sulfoxide adduct (Fig. 1). Given the nucleophilic properties of thiols and several other biological species, it is generally considered that the selectivity towards Cys-SOH maybe difficult to achieve with electrophilic detection tools. ${ }^{47}$ Currently reported examples of electrophilic probes are commercially available compounds such as (i) low reactive NBD-Cl (4) which also lack the chemoselectivity and react with several biological nucleophiles including sulfenic acid (but the resulting adducts are distinguishable due to difference in 
their spectroscopic properties); ${ }^{5},{ }^{28}, 38$ (ii) arylboronates (5) which react with Cys-SOH in a reversible manner and thus have limited utility in proteomic-based sulfenic acid detection ${ }^{52}$ and; (iii) strained cycloalkynes (6) which were recently reported as new, highly reactive sulfenic acid traps $\left(k_{o b s}=13.3 \mathrm{M}^{-1} \mathrm{~s}^{-1}-16.7 \mathrm{M}^{-1} \mathrm{~s}^{-1}\right)$ with > 100-fold higher reactivity than 1,3-dicarbonyls. ${ }^{40}$ Not surprisingly, over the years strained cycloalkynes have been shown to react with other sulfur species such as protein- and small molecule thiols (present in $\mathrm{mM}$ concentration inside the cells) and persulfides. ${ }^{53 \_55}$ Moreover, the product of the reaction of Cys-SOH and strained cycloalkyne $\mathbf{6}$ is an activated vinylic sulfoxide which is a Michaelacceptor and may readily react with biological thiols as well. ${ }^{56}$ As a consequence of the promiscuous reactivity of strained cycloalkynes and the resultant sulfoxide adduct, an additional thiol-blocking step is required to increase the selectivity for sulfenic acid. As mentioned above, even though over the past decade several nucleophilic and electrophilic probes for sulfenic acid detection have been developed and commercialized, the issue of modest reactivity of such probes is well documented. ${ }^{5,26,40}$ Several subsequent publications reported probes with superior reactivity compared to dimedone-based probes at lower or higher pHs. ${ }^{44}, 46,{ }^{47}$ However, such reports generally compared the reactivities of these probes towards Cys-SOH in specific model protein systems where the reactivity could be biased by the protein microenvironment surrounding $\mathrm{Cys}-\mathrm{SOH}$. For this reason a direct comparison of the reactivity of various nucleophilic/electrophilic probes towards $\mathrm{Cys}-\mathrm{SOH}$ and the stability of resulting thioether/sulfoxide adduct under exact same conditions is needed for the better understanding of the reactivity profile of each probe. In order to do so, we chose to utilize our peptide-based sulfenic acid model with subsequent verification in a protein sulfenic acid model. The peptide-based sulfenic acid model exists in the masked form as a cyclic sulfenamide (9) which rearranges to dipeptide sulfenic acid (10) under aqueous conditions (Fig. 3). ${ }^{26}$ Since this model is not influenced by a complex protein microenvironment, the observed reaction rates are independent of factors such as steric hindrance and stabilization/destabilization of sulfenic acid.

\section{Results and Discussion}

Using the peptide-based model and the previously developed LC/MS assay, we initially obtained the pseudo $1^{\text {st }}$ order rate constants $([\mathrm{Nu} / \mathrm{Elec}]=1 \mathrm{mM},[\mathbf{1 0}]=100 \mu \mathrm{M})$ of three nucleophilic (2e, 3a, 7a) and two electrophilic (4, 6a) compounds (Fig. 3). These compounds constitute the reactive component of prevalent and commercially available CysSOH probes such as $\mathbf{2 a - d , ~ 3 , 7 , ~} 4$ and $\mathbf{6}$ (Fig. 2). Nucleophilic cyclohexane-1,3-dione (2e, $\left.k_{\text {obs }}=0.4 \mathrm{~min}^{-1}\right)$, methyl acetoacetate $\left(\mathbf{3 a}, k_{o b s}=0.9 \mathrm{~min}^{-1}\right)$ and $4-$ (ethylthio)cyclopentane-1,3-dione (7a, $k_{o b s}=0.01 \mathrm{~min}^{-1}$ ) successfully reacted with dipeptide-SOH 10 to form corresponding thioether adduct. While 2e and $\mathbf{3 a}$ had similar reactivity under physiological conditions, it is noteworthy that $\mathbf{7 a}$ was 40 -folds less reactive compared to $\mathbf{2 e}$ towards sulfenic acid 10. Electrophilic 4-chloro-7-nitrobenzo[c] $[1,2,5]$ oxadiazole $\left(4, k_{o b s}<0.001 \mathrm{~min}^{-1}\right)$ was extremely slow to react and only a small amount of sulfoxide adduct could be detected even after $48 \mathrm{~h}$ (ESI, Fig. S4). Conversely, while the benzoyl derivative of strained cycloalkyne ( $(1 R, 8 S, 9 S)$-bicyclo[6.1.0]non-4-yn-9yl)methyl benzoate $\left(\mathbf{6 a}, k_{o b s}=\right.$ N.D.) was highly reactive, the corresponding sulfoxide adduct was unstable and quickly rearranged to disulfide (Cbz-Cys-Val-OMe) 2 (ESI, Fig. S5). 
Next, we obtained the pseudo $1^{\text {st }}$ order rate constants of $1 H$-phenalene-1,3(2H)-dione (8a, $k_{o b s}=0.1 \mathrm{~min}^{-1}$ ), recently developed cyclic $C$-nucleophiles 1-benzylpiperidine-2,4-dione $\left(\mathbf{1 1}, k_{\text {obs }}=86.4 \mathrm{~min}^{-1}\right), 1$-benzyl-1 $H$-benzo[c][1,2]thiazin-4(3H)-one 2,2-dioxide (12, $k_{\text {obs }}$ $\left.=190.5 \mathrm{~min}^{-1}\right)$, linear $C$-nucleophiles ((nitromethyl)sulfonyl)benzene $\left(\mathbf{1 3}, k_{\text {obs }}=7.8 \mathrm{~min}^{-1}\right)$, and 2-(phenylsulfonyl)acetonitrile $\left(\mathbf{1 4}, k_{o b s}=78.0 \mathrm{~min}^{-1}\right)$ for the reaction with dipeptide$\mathrm{SOH}$ 10. Due to the opposing effect of resonance stabilization and electron donating naphthyl group, $\mathbf{8 a}$ showed a reduced rate of reaction towards sulfenic acid $\mathbf{1 0}$. Cyclic and linear $C$-nucleophiles 11-14 showed elevated reactivity towards 10. In brief, the reactions of various nucleophiles and electrophiles towards dipeptide-SOH 10 clearly demonstrated the substantially enhanced reactivity of 11-14 compared to currently prevalent probes (Fig. 3).

Subsequently, we examined the reactivity of above-tested nucleophiles and electrophiles towards a protein Cys-SOH. For these studies, we used our well-established Cys64Ser Cys82Ser variant of the recombinant thiol peroxidase, Gpx3. ${ }^{11}$ Incubation of nucleophiles and electrophiles at $100 \mu \mathrm{M}$ concentration with Gpx3-SOH led to the covalent modification of Gpx3-SOH. Of note, while trapping with $2 \mathrm{e}$ was not quantitative, it still captured $~ 50 \%$ Gpx3-SOH (Fig. 4B). Interestingly, even though $\beta$-ketoester 3a showed a higher rate of reaction in the dipeptide-SOH model, the amount of Gpx3-SOH captured was lower than $2 \mathbf{e}$, highlighting the influence of protein microenvironment on reactivity as well as the tendency of the thioether adduct of $\mathbf{3 a}$ to undergo loss of a methylketo (-COMe) group (Fig. 4C). ${ }^{25},{ }^{57}$ Owing to poor reaction rate, 7a failed to capture $\mathrm{Gpx3}-\mathrm{SOH}$, a finding that was consistent with data obtained in the dipeptide-SOH model (Fig. 4D). In contrast to data reported using the $\mathrm{C} 165 \mathrm{~A}$ AhpC-SOH, ${ }^{40}$ the hydroxyl version of strained cycloalkyne 6 captured only a small amount of Gpx3-SOH (Fig. 4E). This result correlates well with the observation that the sulfoxide adduct of $\mathbf{6 a}$ with dipeptide-SOH 10 quickly degrades (ESI, Fig. S5). Phenalene-1,3-dione 8a also showed extremely poor reactivity towards Gpx3-SOH, also consistent with results obtained in the dipeptide-SOH model (Fig. 4F). Finally, akin to their superior reactivity towards the dipeptide-SOH, cyclic C-nucleophiles $\mathbf{1 1}$ and $\mathbf{1 2}$ quantitatively trapped Gpx3-SOH (Fig. 4G-H). Linear C-nucleophiles 13 and 14 also tagged the majority of Gpx3-SOH (Figure 4I-J). These results gratifyingly confirmed the order of reactivity observed in our LC/MS assay using the dipeptide-SOH model system.

We previously showed that due to the difference in reactivity, $\mathrm{p} K_{\mathrm{a}}$, and carbanion stability of C-nucleophiles, the resulting thioether adducts also display a range of stability under reducing conditions. ${ }^{25},{ }^{26}$ As cell contains millimolar concentrations of glutathione (GSH) we tested the ability of this low-molecular weight thiol to reduce the nascent covalent thioether bond formed between $\mathbf{1 0}$ and nucleophiles. Initially thioether adducts of linear Cnucleophiles were shown to be reversible under reducing conditions $-\mathrm{a}$ view strengthened by the stability of thioether adducts $\mathbf{1 5 , 1 7}$ and $\mathbf{1 8}$ and unstable nature of thioether adducts $\mathbf{1 6}\left(t_{1 / 2}=1.4 \mathrm{~h}\right)$ and $22\left(t_{1 / 2}=0.4 \mathrm{~h}\right)$ (Table 1, ESI Fig. S6 - S21 and Fig. S34-S37). ${ }^{25},{ }^{26}$ However, the instability of thioether adduct $19\left(t_{1 / 2}>39 \mathrm{~h}\right)$ formed by cyclic $C$-nucleophile 11 (ESI, Fig. S22 - S25), and the stability of thioether adduct 21 ( $t_{1 / 2}>9$ days) of linear $C$ nucleophile 14 (ESI, Fig. S30 - S33), indicates that the cyclic/linear nature of nucleophiles is not the determining factor with respect to the stability/instability of corresponding adducts (Table 1). Interestingly, enhanced reactivity of a nucleophile is also not the sole criterion for 
reversibility, as illustrated by the stability of thioether adduct $\mathbf{2 0}\left(t_{1 / 2}>18\right.$ days) which results from trapping by the highly reactive cyclic C-nucleophile 12 (Table 1, ESI Fig. S26 S29). Thioether adducts showing $t_{1 / 2}<48 \mathrm{~h}$ were then tested for reversibility in the Gpx3 model. Gpx3-SOH was first labeled with nucleophiles 3a, 11 and 14. Subsequently, each Gpx3-Nu adduct was subjected to $\mathrm{mM}$ glutathione (GSH), dithiothreitol (DTT) or the phosphine-based reductant, TCEP. Correlating with the reversibility trends observed in the reduction of dipeptide-based model, Gpx3-S-Nu adducts formed by $\beta$-ketoester $\mathbf{3 a}$ and phenylsulfonylacetonitrile $\mathbf{1 4}$ were almost completely reversible while the adduct corresponding to $\mathbf{1 1}$ showed some reversibility under reducing conditions (ESI Fig. S50).

In light of the aforementioned stability data, we subsequently explored the effect of C-2 substitution on the reactivity of nucleophiles towards sulfenic acid. In this regard, one key issue is that a tertiary carbanion is less stable than a secondary carbanion. Moreover, upon reaction with sulfenic acid, a C-2 substituted nucleophile would be 'locked' in the keto tautomer. Such a conformational lock could potentially result in unique spectroscopic properties (i.e., UV/Vis or fluorescence) of the nucleophile before and after reaction with sulfenic acid. Such difference in UV/Vis absorption or fluorescence may be exploited to develop a 'turn-on/turn-off switch' based sulfenic acid detection strategy. A representative example of a nucleophile undergoing such change in spectroscopic properties is 2substituted derivatives of phenalene-1,3-dione (8a). Keto-enol tautomerism is facile for compound 8a readily and, upon reaction with Cys- $\mathrm{SOH}$, keto product 18 can easily rearrange to give enol 18' (Fig. 5A), whereas the thioether derivative of 2-substitutedphenalene-1,3-dione (23) would be locked in the keto form 24 (Fig. 5B) resulting in turn-on fluorescence. ${ }^{58}$ Although new spectral properties of the resulting thioether adduct is an attractive possibility, the effect of C-2 substitution by an electron-donating group (EDG) or electron-withdrawing group (EWG) on nucleophile reactivity has not been studied.

To examine the issue of C-2 substitution, we studied the reactivity of dipeptide sulfenic acid 10 with C-2 methylated (EDG) and C-2 fluorinated (EWG) derivatives of three nucleophiles - (a) cyclohexane-1,3-dione (2e), (b) $1 H$-phenalene-1,3(2H)-dione (8a), and (c) diethylmalonate (29). The analogs were prepared following literature reported procedures. ${ }^{59}$ The kinetic studies data are summarized in Table 2. Briefly, while 2-methylcyclohexane-1,3dione $\left(\mathbf{2 5}, k_{o b s}>0.4 \mathrm{~min}^{-1}\right)$ showed slightly higher reactivity than $\mathbf{2 e}\left(k_{o b s}=0.4 \mathrm{~min}^{-1}\right), 2$ fluorocyclohexane-1,3-dione ( $\left.\mathbf{2 6}, k_{o b s}<0.001 \mathrm{~min}^{-1}\right)$ was very slow to react (Table 2A). Conversely, both 2-methyl-1 $H$-phenalene-1,3(2H)-dione (27, $\left.k_{\text {obs }}=0.002 \mathrm{~min}^{-1}\right)$ and 2fluoro-1 $H$-phenalene-1,3(2H)-dione $\left(\mathbf{2 8}, k_{o b s}<0.001 \mathrm{~min}^{-1}\right)$ showed reduced reactivity, as compared to $\mathbf{8 a}\left(k_{o b s}=0.1 \mathrm{~min}^{-1}\right)$ (Table $\left.2 \mathrm{~B}\right)$. Diethylmalonate $\left(\mathbf{2 9}, k_{o b s}=0.1 \mathrm{~min}^{-1}\right)$ exhibited similar reactivity to $\mathbf{8 a}$ and its $\mathrm{C}-2$ substituted derivatives diethyl 2methylmalonate $\left(\mathbf{2 9}, k_{o b s}<0.001 \mathrm{~min}^{-1}\right)$ and diethyl 2-fluoromalonate $\left(\mathbf{3 0}, k_{o b s}<0.001\right.$ $\mathrm{min}^{-1}$ ) were extremely slow to react as well (Table 2C).

The poor reactivity of C-2 fluorinated analogs 26,28 and $\mathbf{3 1}$ may be attributed to the strongly electron-withdrawing effect resulting in hydration of carbonyl group. However, the reactivity of C-2 methylated analogs towards dipeptide-SOH 10 is more complex to explain. While 25 showed slightly enhanced reactivity compared to $\mathbf{2 e}$ the resulting thioether adduct 
quickly underwent carbonyl hydration due to the electron-withdrawing effect of -SR group (ESI Fig. S51 - S52). Similar carbonyl hydration was observed in case of thioether adduct of 27 (ESI Fig. S53). Another consequence of hydration is that the diketo nucleophile becomes a poorer leaving group and the corresponding thioether adducts are stable under reducing conditions (ESI Fig. S38 - S41). The hydration effect is not observed in case of the thioether adduct 15 of $2 \mathbf{e}$ or 18 of $8 \mathbf{a}$ because under aqueous conditions they readily undergo ketoenol tautomerism and favor the enol form. Diethylmalonate $\mathbf{2 9}$ has a comparatively high $\mathrm{p} K_{\mathrm{a}}$ value of 13 and its C-2 methyl derivative $\mathbf{3 0}$ is expected to have an even higher $\mathrm{p} K_{\mathrm{a}}$, which would result in reduced reactivity towards sulfenic acid 10, as was observed. In general, C-2 substitution is detrimental for the reactivity of $\mathrm{C}$-nucleophiles towards sulfenic acid and reduced the reaction rates by 100 -folds or more.

Like many other critical post-translational modifications, such as phosphorylation and methylation, protein sulfenylation is reversible with an estimated half-life occurring on the timescale of minutes. ${ }^{5}$ In the case of sulfenic acid, its transient nature is often attributed to its reaction with GSH and protein thiol group and these reactions compete with chemical probes. We illustrate this issue by calculating the percent of $\underline{\text { Human }} \underline{\text { Serum }}$ Albumin sulfenic

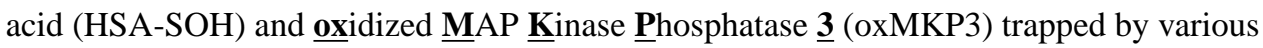
nucleophiles in the presence of mM GSH (ESI, Fig. S54). It is clear from the calculations that in both cases, the majority of C-nucleophiles on which current probes are based would capture only a fraction of sulfenic acid (Table 3 , entries $2 \mathrm{e}, 3 \mathrm{a}, 7 \mathrm{a}$ and $8 \mathrm{a}$ ). By contrast, the same calculations with more recently developed cyclic and linear C-nucleophiles predict near quantitative capture of both HSA-SOH and oxMKP3, even at low nucleophile concentration $([\mathrm{Nu}]=100 \mu \mathrm{M})$ (Table 3, entries 11-14). Collectively, these data highlight key differences among chemical probes for detecting sulfenic acid in the face of competing biological reactions.

The impact of the slow reaction rates of currently used probes in the detection and quantitative analysis of protein-SOH is countered by using large amount of starting biological material (> $30 \mathrm{mg})$, higher probe concentrations $(5 \mathrm{mM}-10 \mathrm{mM})$ and longer incubation periods. ${ }^{19},{ }^{41}$ It is speculated that higher probe concentrations and longer incubation times increase the rate of false positive identification. ${ }^{21}$ Thus, an ideal probe for proteomic studies would have the following characteristics: (i) sufficiently fast rate of reaction with protein-SOH at low probe concentrations; (ii) form stable adducts with protein-SOH; and (iii) retain chemoselectivity for sulfenic acid. Many of the commercially available probes do not satisfy one or more of these criterions. For example, most commonly used probes such as DYn-2 (2a), DAz-2 (2b), DCP-Bio1 (2c), DCP-Rho1 (2d) and many more are based on cyclohexane1,3-dione (2e) core, which has modest reactivity towards $\mathrm{SOH}\left(k_{\text {obs }}=0.4 \mathrm{~min}^{-1}\right)$. Factors such as the poor reactivity of cyclopentane-1,3-dione ( $k_{\text {obs }}$ $=0.01 \mathrm{~min}^{-1}$ ), strongly anionic nature and presence of a biotin group (poor cell permeability and increased complexity for peptide identification) make BP1 (7) less attractive for proteomic analysis of protein-SOH. On the other hand, while $\beta$-ketoester-based Alk- $\beta$-KE (3) gives reaction rates $\left(k_{\text {obs }}=0.9 \mathrm{~min}^{-1}\right)$ similar to $\mathbf{2 e}$, the corresponding thioether adduct is susceptible to reduction as well as deacetylation. Recently reported strained cycloalkyne BCN-Bio (6) was highly reactive towards small molecule $\mathrm{SOH}$ (10), but the corresponding 
sulfoxide adduct was highly unstable under the conditions of LC/MS analysis. Moreover, BCN-bio (6) showed poor reactivity towards $\mathrm{Gpx} 3-\mathrm{SOH}$ and is not chemoselective for sulfenic acid. ${ }^{53 \_55}$ The concept of exploiting 2-substituted-phenalene-1,3(2H)-diones $(\mathbf{8}, \mathbf{2 7}$, 28) as fluorescent turn-on probes using conformational-lock is attractive, however such compounds suffered from poor reactivity towards dipeptide-SOH $\mathbf{1 0}\left(k_{o b s}<0.001 \mathrm{~min}^{-1}\right)$ as well as Gpx3-SOH.

In an effort to address above limitations and develop "next-generation" sulfenic acid probes, we performed side-by-side comparisons with recently developed cyclic $(\mathbf{1 1}, \mathbf{1 2})$ and linear C-nucleophiles $(\mathbf{1 3}, \mathbf{1 4})$. With $k_{\text {obs }}$ ranging from $7.8 \mathrm{~min}^{-1}$ to $190.5 \mathrm{~min}^{-1}$, C-nucleophiles 11-14 showed 20- to 500-fold rate enhancement, compared to 2e. Moreover, these nucleophiles quantitatively trapped Gpx3-SOH at low concentrations $(100 \mu \mathrm{M})$. Thioether adducts resulting from reaction of cyclic 11 and linear 14 with sulfenic acid 10 (i.e., 19 and 22) exhibited varying stability under reducing conditions. With a $t_{1 / 2}=39 \mathrm{~h}$, thioether 19 was substantially more stable than $\mathbf{2 2}\left(t_{1 / 2}=0.4 \mathrm{~h}\right)$, indicating that cyclic C-nucleophile $\mathbf{1 1}$ may be suitable for future probe development. Thioether adducts $\mathbf{2 0}$ and $\mathbf{2 1}$ showed robust stability under reducing conditions, suggesting that C-nucleophiles $\mathbf{1 2}$ and $\mathbf{1 3}$ are excellent candidates for "next-generation" sulfenic acid probes.

\section{Conclusion}

In conclusion, we have compared the reactivity of commonly used/commercially available nucleophilic and electrophilic probes with recently developed cyclic and linear Cnucleophiles with sulfenic acid. Using the rate constants obtained from our dipeptide-SOH model, and comparing them with known rates of glutathionylation for protein-SOH, our data indicate that while current probes are sufficient for qualitative analysis, they are not capable of quantitative trapping and may not be well-suited to detect more short-lived sulfenic acid modifications. By extension, "next-generation" probes with superior reaction rates and sufficient stability will enable more comprehensive analysis of the sulfenylome. Another important consideration is the effect of probe/protein structure on chemical reactivity. Along these lines, to obtain deep coverage of the sulfenylome, it may be valuable to explore multiple probes with varying reactivity and distinct structural features. Further, we have established the reversibility of the thioether adduct resulting from $\beta$-ketoester-based Alk- $\beta$ KE (3) and other nucleophiles, such as $\mathbf{1 4}$, under reducing conditions encountered during trapping or in common use during proteomic sample preparation. Such reversibility can result in false negative results and, thus, it is critical to evaluate the stability of thioether (or sulfoxide) adducts formed by the reaction of nucleophilic (or electrophilic) probes (Fig. 6). Finally, we highlight the utility of dipeptide sulfenic acid $\mathbf{1 0}$ as model for screening and a facile way to compare the reactivity of nucleophiles and electrophiles with sulfenic acid. Moreover, dipeptide-SOH 10 provides a straightforward way to prepare the corresponding thioether (or sulfoxide) adducts in order to study their stability under various conditions.

\section{Supplementary Material}

Refer to Web version on PubMed Central for supplementary material. 


\section{Acknowledgments}

We thank Dr. Brent Martin (University of Michigan) for conversations pertaining to 2-substitutedphenalene-1,3(2H)-diones. This work is supported by the National Institutes of Health under awards No. R01 GM102187 and R01 CA174864 to K.S.C.

\section{References}

1. Reddie KG, Carroll KS. Expanding the functional diversity of proteins through cysteine oxidation. Curr Opin Chem Biol. 2008; 12:746-754. [PubMed: 18804173]

2. Paulsen CE, Carroll KS. Orchestrating redox signaling networks through regulatory cysteine switches. ACS Chem Biol. 2010; 5:47-62. [PubMed: 19957967]

3. Lo Conte M, Carroll KS. The redox biochemistry of protein sulfenylation and sulfinylation. J Biol Chem. 2013; 288:26480-26488. [PubMed: 23861405]

4. Paulsen CE, Carroll KS. Cysteine-mediated redox signaling: chemistry, biology, and tools for discovery. Chem Rev. 2013; 113:4633-4679. [PubMed: 23514336]

5. Gupta V, Carroll KS. Sulfenic acid chemistry, detection and cellular lifetime. Biochim Biophys Acta. 2014; 1840:847-875. [PubMed: 23748139]

6. Chouchani ET, Kazak L, Jedrychowski MP, Lu GZ, Erickson BK, Szpyt J, Pierce KA, LaznikBogoslavski D, Vetrivelan R, Clish CB, et al. Mitochondrial ROS regulate thermogenic energy expenditure and sulfenylation of UCP1. Nature. 2016; 532:112-116. [PubMed: 27027295]

7. Denu JM, Tanner KG. Specific and reversible inactivation of protein tyrosine phosphatases by hydrogen peroxide: evidence for a sulfenic acid intermediate and implications for redox regulation. Biochemistry. 1998; 37:5633-5642. [PubMed: 9548949]

8. Carballal S, Radi R, Kirk MC, Barnes S, Freeman BA, Alvarez B. Sulfenic acid formation in human serum albumin by hydrogen peroxide and peroxynitrite. Biochemistry. 2003; 42:9906-9914. [PubMed: 12924939]

9. Depuydt M, Leonard SE, Vertommen D, Denoncin K, Morsomme P, Wahni K, Messens J, Carroll KS, Collet JF. A periplasmic reducing system protects single cysteine residues from oxidation. Science. 2009; 326:1109-1111. [PubMed: 19965429]

10. Leonard SE, Reddie KG, Carroll KS. Mining the thiol proteome for sulfenic acid modifications reveals new targets for oxidation in cells. ACS Chem Biol. 2009; 4:783-799. [PubMed: 19645509]

11. Paulsen CE, Carroll KS. Chemical dissection of an essential redox switch in yeast. Chem Biol. 2009; 16:217-225. [PubMed: 19230722]

12. Seo YH, Carroll KS. Profiling protein thiol oxidation in tumor cells using sulfenic acid-specific antibodies. Proc Natl Acad Sci U S A. 2009; 106:16163-16168. [PubMed: 19805274]

13. Leonard SE, Garcia FJ, Goodsell DS, Carroll KS. Redox-based probes for protein tyrosine phosphatases. Angew Chem Int Ed Engl. 2011; 50:4423-4427. [PubMed: 21504031]

14. Barrett TJ, Pattison DI, Leonard SE, Carroll KS, Davies MJ, Hawkins CL. Inactivation of thioldependent enzymes by hypothiocyanous acid: role of sulfenyl thiocyanate and sulfenic acid intermediates. Free Radic Biol Med. 2012; 52:1075-1085. [PubMed: 22248862]

15. Paulsen CE, Truong TH, Garcia FJ, Homann A, Gupta V, Leonard SE, Carroll KS. Peroxidedependent sulfenylation of the EGFR catalytic site enhances kinase activity. Nat Chem Biol. 2012; 8:57-64. [PubMed: 22158416]

16. Svoboda LK, Reddie KG, Zhang L, Vesely ED, Williams ES, Schumacher SM, O'Connell RP, Shaw R, Day SM, Anumonwo JM, et al. Redox-sensitive sulfenic acid modification regulates surface expression of the cardiovascular voltage-gated potassium channel Kv1.5. Circ Res. 2012; 111:842-853. [PubMed: 22843785]

17. Alili L, Sack M, von Montfort C, Giri S, Das S, Carroll KS, Zanger K, Seal S, Brenneisen P. Downregulation of tumor growth and invasion by redox-active nanoparticles. Antioxid Redox Signal. 2013; 19:765-778. [PubMed: 23198807]

18. Kulathu Y, Garcia FJ, Mevissen TE, Busch M, Arnaudo N, Carroll KS, Barford D, Komander D. Regulation of A20 and other OTU deubiquitinases by reversible oxidation. Nat Commun. 2013; 4:1569. [PubMed: 23463012] 
19. Yang J, Gupta V, Carroll KS, Liebler DC. Site-specific mapping and quantification of protein Ssulphenylation in cells. Nat Commun. 2014; 5:4776. [PubMed: 25175731]

20. Gould NS, Evans P, Martinez-Acedo P, Marino SM, Gladyshev VN, Carroll KS, Ischiropoulos H. Site-Specific Proteomic Mapping Identifies Selectively Modified Regulatory Cysteine Residues in Functionally Distinct Protein Networks. Chem Biol. 2015; 22:965-975. [PubMed: 26165157]

21. Devarie-Baez NO, Silva Lopez EI, Furdui CM. Biological chemistry and functionality of protein sulfenic acids and related thiol modifications. Free Radical Research. 2016; 50:172-194. [PubMed: 26340608]

22. Zito E, Hansen HG, Yeo GS, Fujii J, Ron D. Endoplasmic reticulum thiol oxidase deficiency leads to ascorbic acid depletion and noncanonical scurvy in mice. Mol Cell. 2012; 48:39-51. [PubMed: 22981861]

23. Truong TH, Carroll KS. Redox regulation of epidermal growth factor receptor signaling through cysteine oxidation. Biochemistry. 2012; 51:9954-9965. [PubMed: 23186290]

24. Truong TH, Carroll KS. Redox regulation of protein kinases. Crit Rev Biochem Mol Biol. 2013; 48:332-356. [PubMed: 23639002]

25. Gupta V, Carroll KS. Rational design of reversible and irreversible cysteine sulfenic acid-targeted linear C-nucleophiles. Chem Commun (Camb). 2016; 52:3414-3417. [PubMed: 26878905]

26. Gupta V, Carroll KS. Profiling the Reactivity of Cyclic C-Nucleophiles towards Electrophilic Sulfur in Cysteine Sulfenic Acid. Chem Sci. 2016; 7:400-415. [PubMed: 26819701]

27. Visscher M, Arkin MR, Dansen TB. Covalent targeting of acquired cysteines in cancer. Curr Opin Chem Biol. 2016; 30:61-67. [PubMed: 26629855]

28. Ellis HR, Poole LB. Novel application of 7-chloro-4-nitrobenzo-2-oxa-1,3-diazole to identify cysteine sulfenic acid in the AhpC component of alkyl hydroperoxide reductase. Biochemistry. 1997; 36:15013-15018. [PubMed: 9398227]

29. Poole LB, Zeng BB, Knaggs SA, Yakubu M, King SB. Synthesis of chemical probes to map sulfenic acid modifications on proteins. Bioconjug Chem. 2005; 16:1624-1628. [PubMed: 16287263]

30. Poole LB, Klomsiri C, Knaggs SA, Furdui CM, Nelson KJ, Thomas MJ, Fetrow JS, Daniel LW, King SB. Fluorescent and affinity-based tools to detect cysteine sulfenic acid formation in proteins. Bioconjug Chem. 2007; 18:2004-2017. [PubMed: 18030992]

31. Reddie KG, Seo YH, Muse Iii WB, Leonard SE, Carroll KS. A chemical approach for detecting sulfenic acid-modified proteins in living cells. Mol Biosyst. 2008; 4:521-531. [PubMed: 18493649]

32. Seo YH, Carroll KS. Facile synthesis and biological evaluation of a cell-permeable probe to detect redox-regulated proteins. Bioorg Med Chem Lett. 2009; 19:356-359. [PubMed: 19081252]

33. Leonard SE, Carroll KS. Chemical 'omics' approaches for understanding protein cysteine oxidation in biology. Curr Opin Chem Biol. 2011; 15:88-102. [PubMed: 21130680]

34. Seo YH, Carroll KS. Quantification of protein sulfenic acid modifications using isotope-coded dimedone and iododimedone. Angew Chem Int Ed Engl. 2011; 50:1342-1345. [PubMed: 21290508]

35. Truong TH, Garcia FJ, Seo YH, Carroll KS. Isotope-coded chemical reporter and acid-cleavable affinity reagents for monitoring protein sulfenic acids. Bioorg Med Chem Lett. 2011; 21:50155020. [PubMed: 21601453]

36. Garcia FJ, Carroll KS. Redox-based probes as tools to monitor oxidized protein tyrosine phosphatases in living cells. Eur J Med Chem. 2014; 88:28-33. [PubMed: 24974258]

37. Martinez-Acedo P, Gupta V, Carroll KS. Proteomic analysis of peptides tagged with dimedone and related probes. J Mass Spectrom. 2014; 49:257-265. [PubMed: 24719340]

38. Pan J, Carroll KS. Chemical biology approaches to study protein cysteine sulfenylation. Biopolymers. 2014; 101:165-172. [PubMed: 23576224]

39. Brewer TF, Garcia FJ, Onak CS, Carroll KS, Chang CJ. Chemical approaches to discovery and study of sources and targets of hydrogen peroxide redox signaling through NADPH oxidase proteins. Annu Rev Biochem. 2015; 84:765-790. [PubMed: 26034893]

40. Poole TH, Reisz JA, Zhao WL, Poole LB, Furdui CM, King SB. Strained Cycloalkynes as New Protein Sulfenic Acid Traps. J Am Chem Soc. 2014; 136:6167-6170. [PubMed: 24724926] 
41. Yang J, Gupta V, Tallman KA, Porter NA, Carroll KS, Liebler DC. Global, in situ, site-specific analysis of protein S-sulfenylation. Nat Protoc. 2015; 10:1022-1037. [PubMed: 26086405]

42. Garcia FJ, Carroll KS. An immunochemical approach to detect oxidized protein tyrosine phosphatases using a selective C-nucleophile tag. Mol Biosyst. 2016

43. Yang J, Carroll KS, Liebler DC. The Expanding Landscape of the Thiol Redox Proteome. Mol Cell Proteomics. 2016; 15:1-11. [PubMed: 26518762]

44. Qian J, Klomsiri C, Wright MW, King SB, Tsang AW, Poole LB, Furdui CM. Simple synthesis of 1,3-cyclopentanedione derived probes for labeling sulfenic acid proteins. Chem Commun (Camb). 2011; 47:9203-9205. [PubMed: 21738918]

45. Wani R, Qian J, Yin L, Bechtold E, King SB, Poole LB, Paek E, Tsang AW, Furdui CM. Isoformspecific regulation of Akt by PDGF-induced reactive oxygen species. Proc Natl Acad Sci U S A. 2011; 108:10550-10555. [PubMed: 21670275]

46. Qian J, Wani R, Klomsiri C, Poole LB, Tsang AW, Furdui CM. A simple and effective strategy for labeling cysteine sulfenic acid in proteins by utilization of beta-ketoesters as cleavable probes. Chem Commun (Camb). 2012; 48:4091-4093. [PubMed: 22430672]

47. Furdui CM, Poole LB. Chemical approaches to detect and analyze protein sulfenic acids. Mass Spectrometry Reviews. 2014; 33:126-146. [PubMed: 24105931]

48. Pan J, Carroll KS. Light-Mediated Sulfenic Acid Generation from Photocaged Cysteine Sulfoxide. Org Lett. 2015; 17:6014-6017. [PubMed: 26641493]

49. Waszczak C, Akter S, Eeckhout D, Persiau G, Wahni K, Bodra N, Van Molle I, De Smet B, Vertommen D, Gevaert K, et al. Sulfenome mining in Arabidopsis thaliana. Proc Natl Acad Sci U S A. 2014; 111:11545-11550. [PubMed: 25049418]

50. Akter S, Huang J, Waszczak C, Jacques S, Gevaert K, Van Breusegem F, Messens J. Cysteines under ROS attack in plants: a proteomics view. J Exp Bot. 2015; 66:2935-2944. [PubMed: 25750420]

51. Akter S, Huang J, Bodra N, De Smet B, Wahni K, Rombaut D, Pauwels J, Gevaert K, Carroll K, Van Breusegem F, et al. DYn-2 Based Identification of Arabidopsis Sulfenomes. Mol Cell Proteomics. 2015; 14:1183-1200. [PubMed: 25693797]

52. Liu CT, Benkovic SJ. Capturing a sulfenic acid with arylboronic acids and benzoxaborole. J Am Chem Soc. 2013; 135:14544-14547. [PubMed: 24050501]

53. Sun Y, Ma XW, Cheng K, Wu BY, Duan JL, Chen H, Bu LH, Zhang RP, Hu XM, Deng ZX, et al. Strained Cyclooctyne as a Molecular Platform for Construction of Multimodal Imaging Probes. Angew Chem Int Edit. 2015; 54:5981-5984.

54. Galardon E, Padovani D. Reactivity of persulfides toward strained bicyclo[6.1.0]nonyne derivatives: relevance to chemical tagging of proteins. Bioconjug Chem. 2015; 26:1013-1016. [PubMed: 26011436]

55. Tian H, Sakmar TP, Huber T. A simple method for enhancing the bioorthogonality of cyclooctyne reagent. Chem Commun (Camb). 2016; 52:5451-5454. [PubMed: 27009873]

56. Nicponski DR, Marchi JM. Selectivity Reversal during Thia-Michael Additions Using Tetrabutylammonium Hydroxide: Operationally Simple and Extremely High Turnover. Synthesis. 2014; 46:1725-1730.

57. Ruddraraju KV, Parsons ZD, Llufrio EM, Frost NL, Gates KS. Reactions of 1,3-Diketones with a Dipeptide Isothiazolidin-3-one: Toward Agents That Covalently Capture Oxidized Protein Tyrosine Phosphatase 1B. The Journal of Organic Chemistry. 2015; 80:12015-12026. [PubMed: 26517018]

58. Wang S, Xu S, Hu G, Bai X, James TD, Wang L. A Fluorescent Chemodosimeter for Live-Cell Monitoring of Aqueous Sulfides. Analytical Chemistry. 2016; 88:1434-1439. [PubMed: 26691536]

59. Sloop JC, Churley M, Guzman A, Moseley S, Stalker S, Weyand J, Yi J. Synthesis and Reactivity of Fluorinated Cyclic Ketones: Initial Findings. American Journal of Organic Chemistry. 2014; $4: 1-10$. 
Nucleophiles (Nu)

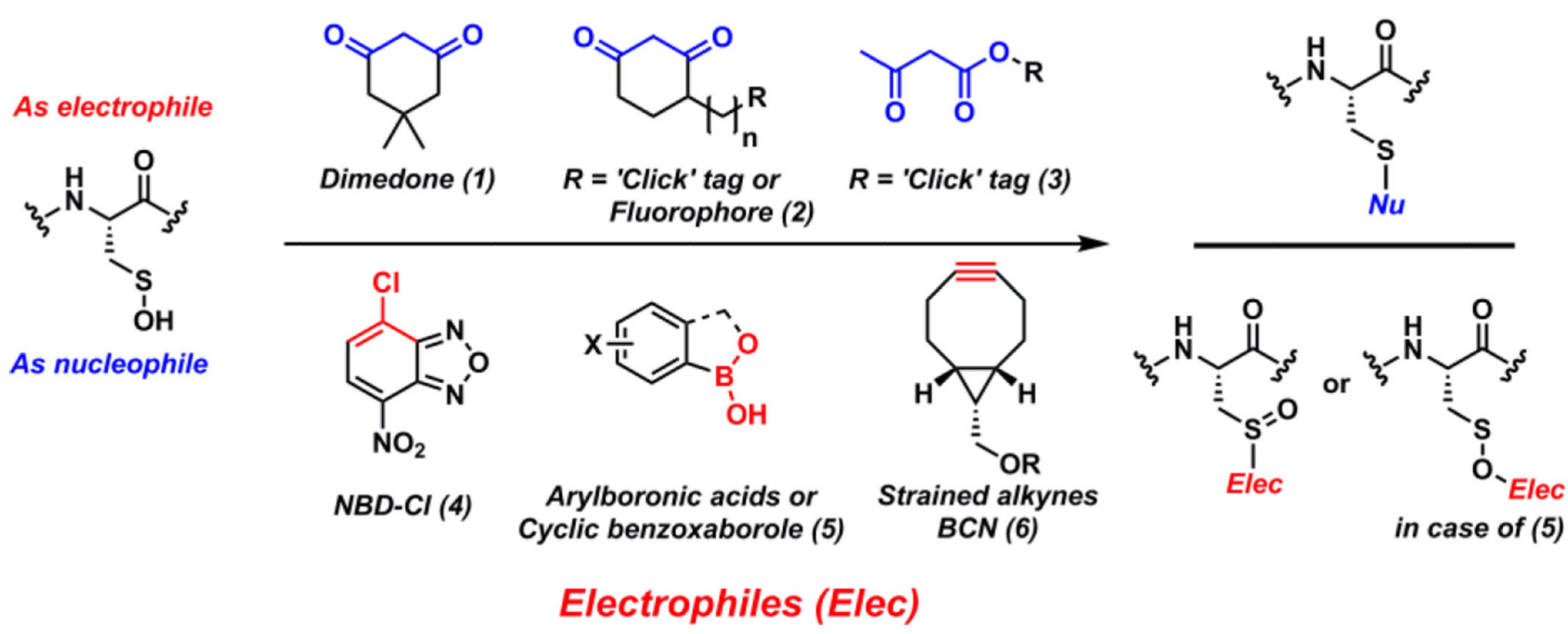

Fig. 1.

Dual chemical reactivity of sulfenic acid. 


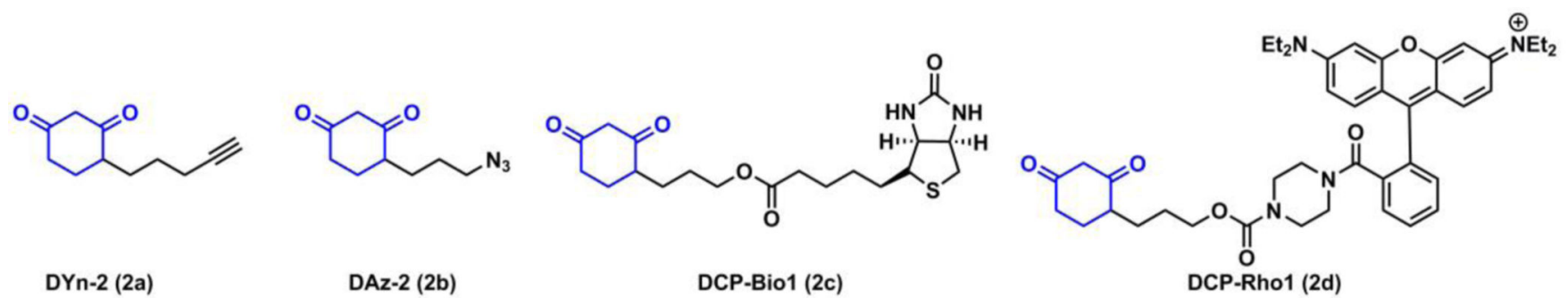<smiles>C#CCCOC(=O)CC(C)=O</smiles><smiles></smiles><smiles>[R]C1C(=O)c2cccc3c(O)ccc(c23)C1=O</smiles>

(8)<smiles>O=[N+]([O-])c1ccc(Cl)c2nonc12</smiles>

$N B D-C l(4)$

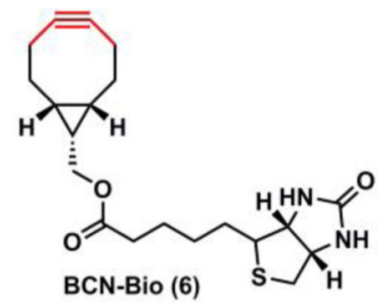

$R=$ Me or $F$

$\mathbf{R}^{\prime}$ = 'click' handle

Fig. 2.

Nucleophilic and electrophilic probes reported for detecting sulfenic acid. 


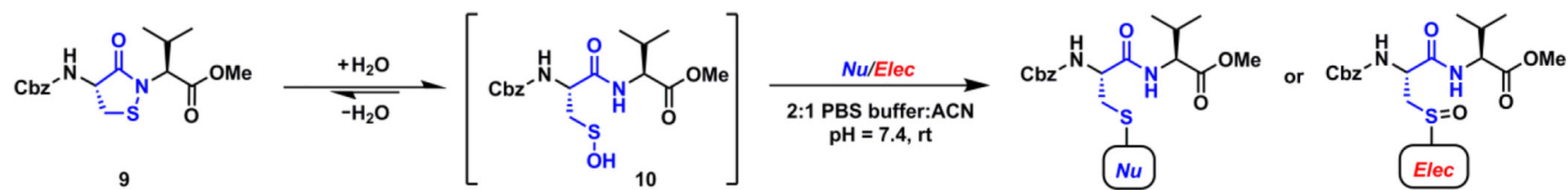

9

10
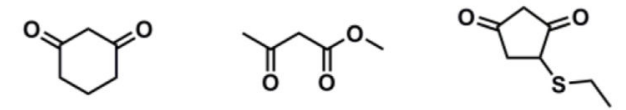

$7 a$
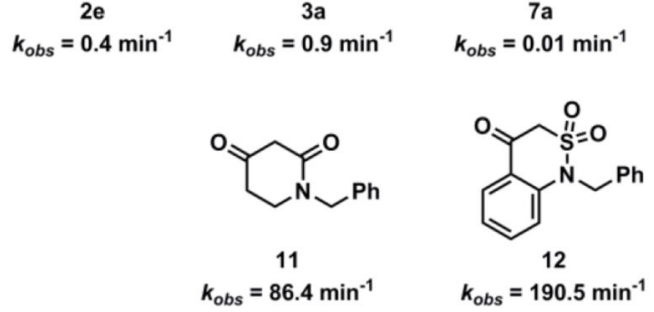

$k_{\text {obs }}=190.5 \mathrm{~min}^{-1}$

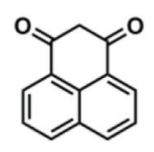

$8 \mathrm{a}$

$k_{\text {obs }}=0.1 \min ^{-1}$



4

$k_{\text {obs }} \leq 0.001 \mathrm{~min}^{-1}$
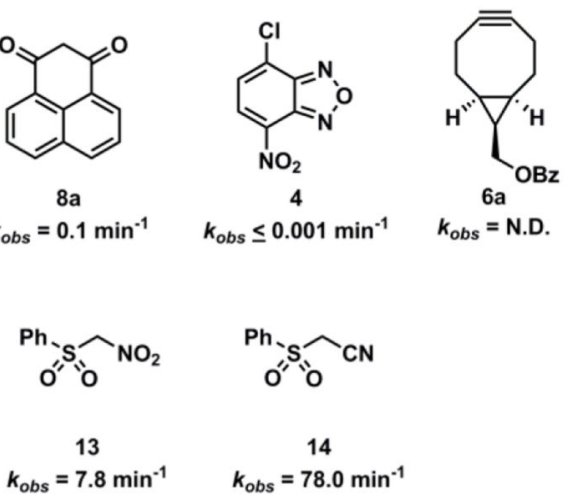

Fig. 3.

Nucleophiles and electrophiles tested for reactivity with sulfenic acid $\mathbf{1 0 .}$ 

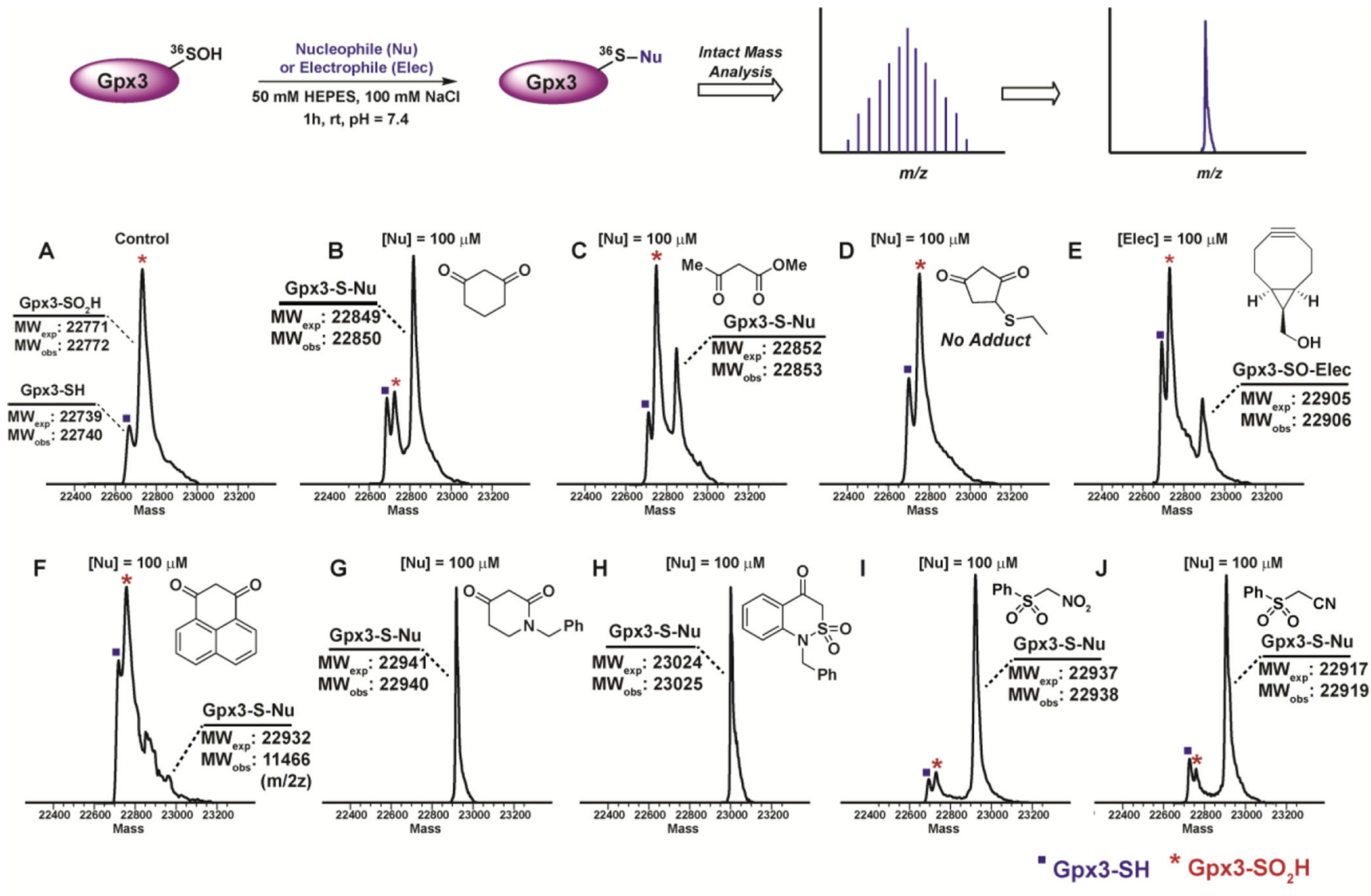

Fig. 4.

Reactivity of nucleophiles and electrophiles with Gpx3-SOH. 
A<smiles>O=C1CC(=O)c2cccc3cccc1c23</smiles>

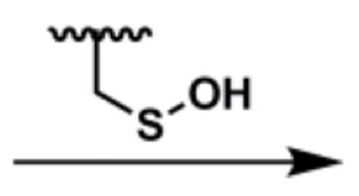

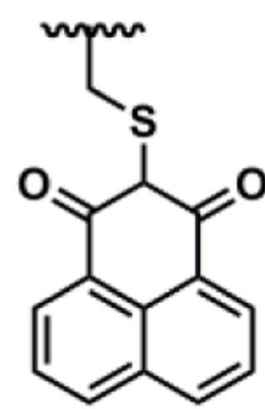

18

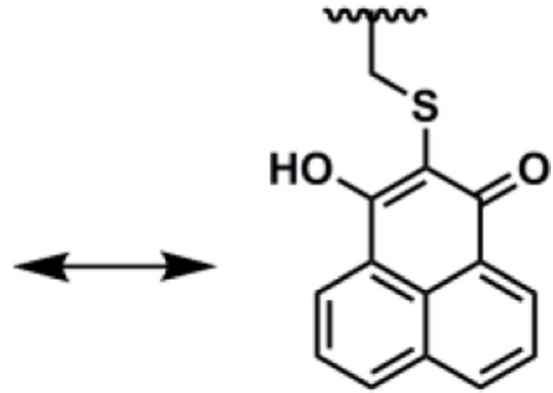

18

B<smiles>[R]C1C(=O)c2cccc3cccc(c23)C1=O</smiles>

23

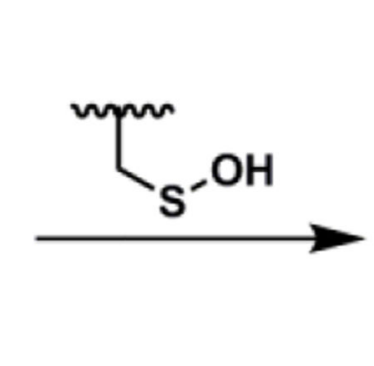

mpn



24<smiles></smiles>

24'

Fig. 5.

Effect of C-2 substitution on the UV-vis and fluorescence properties of the nucleophiles and corresponding thioether adducts. 


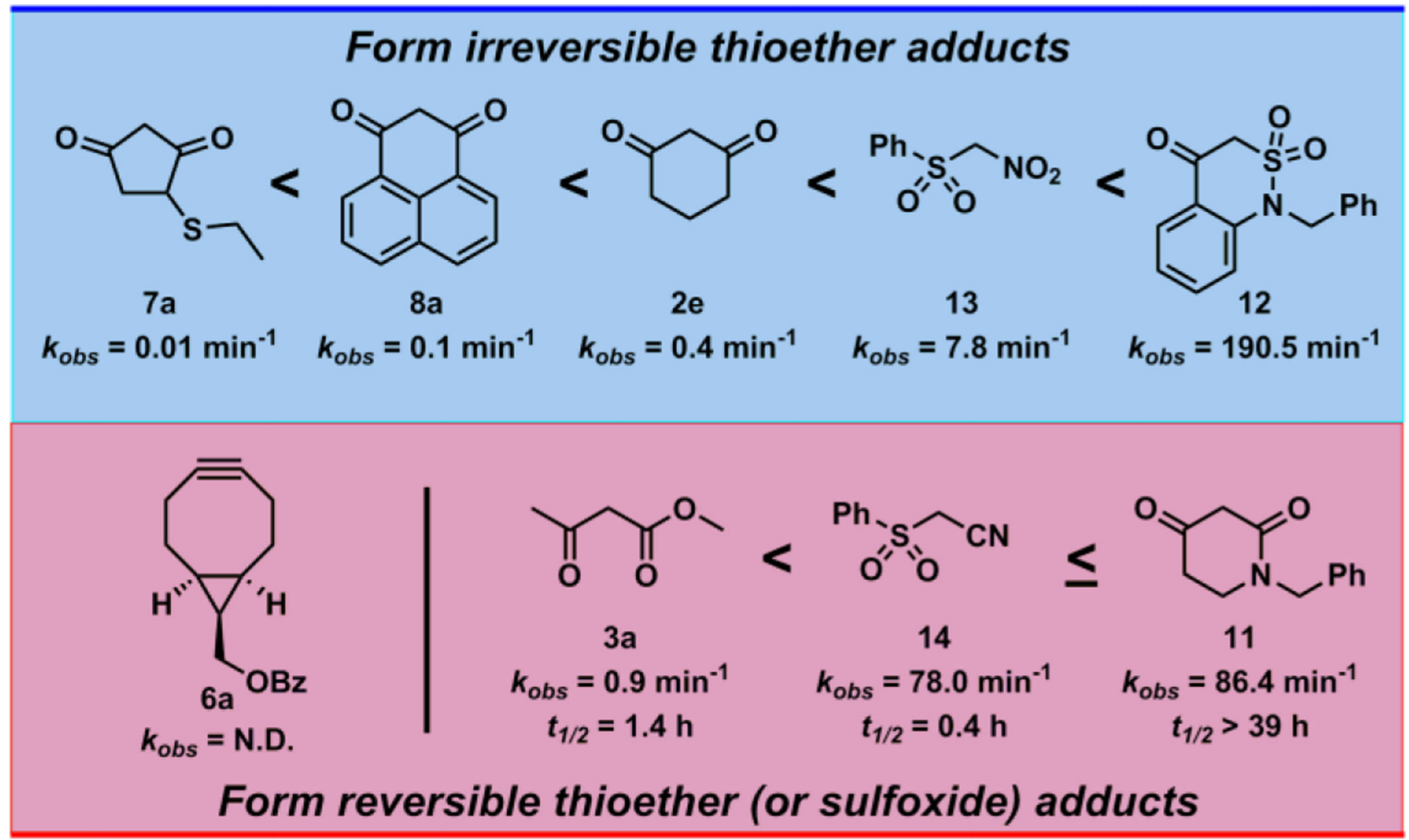

Fig. 6.

Ratification of various nucleophiles and electrophiles on the basis of sulfenic acid reactivity and stability/reversibility of corresponding thioether (or sulfoxide) adduct. 

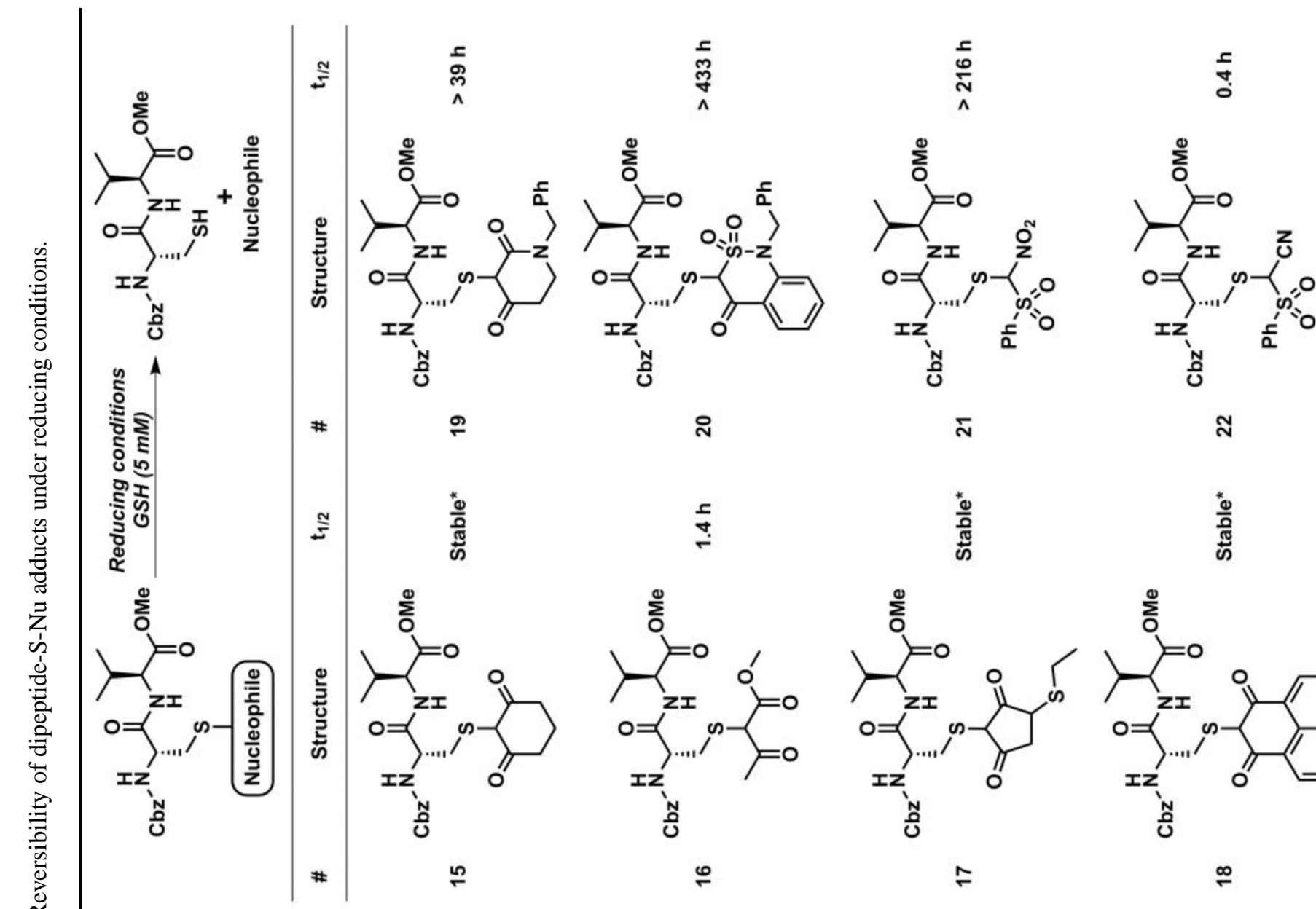


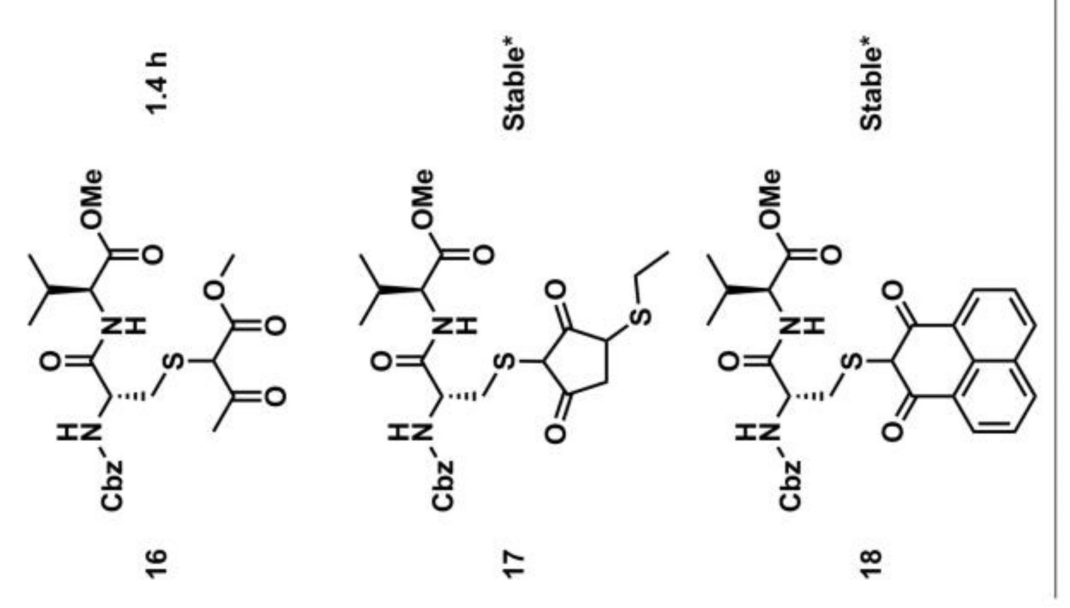

Bioconjug Chem. Author manuscript; available in PMC 2017 May 18. 


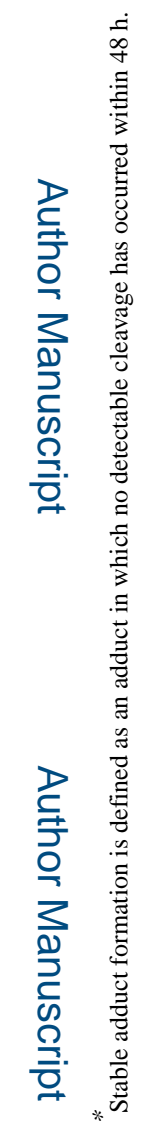

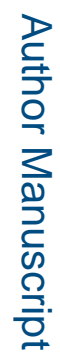

롤

Bioconjug Chem. Author manuscript; available in PMC 2017 May 18. 

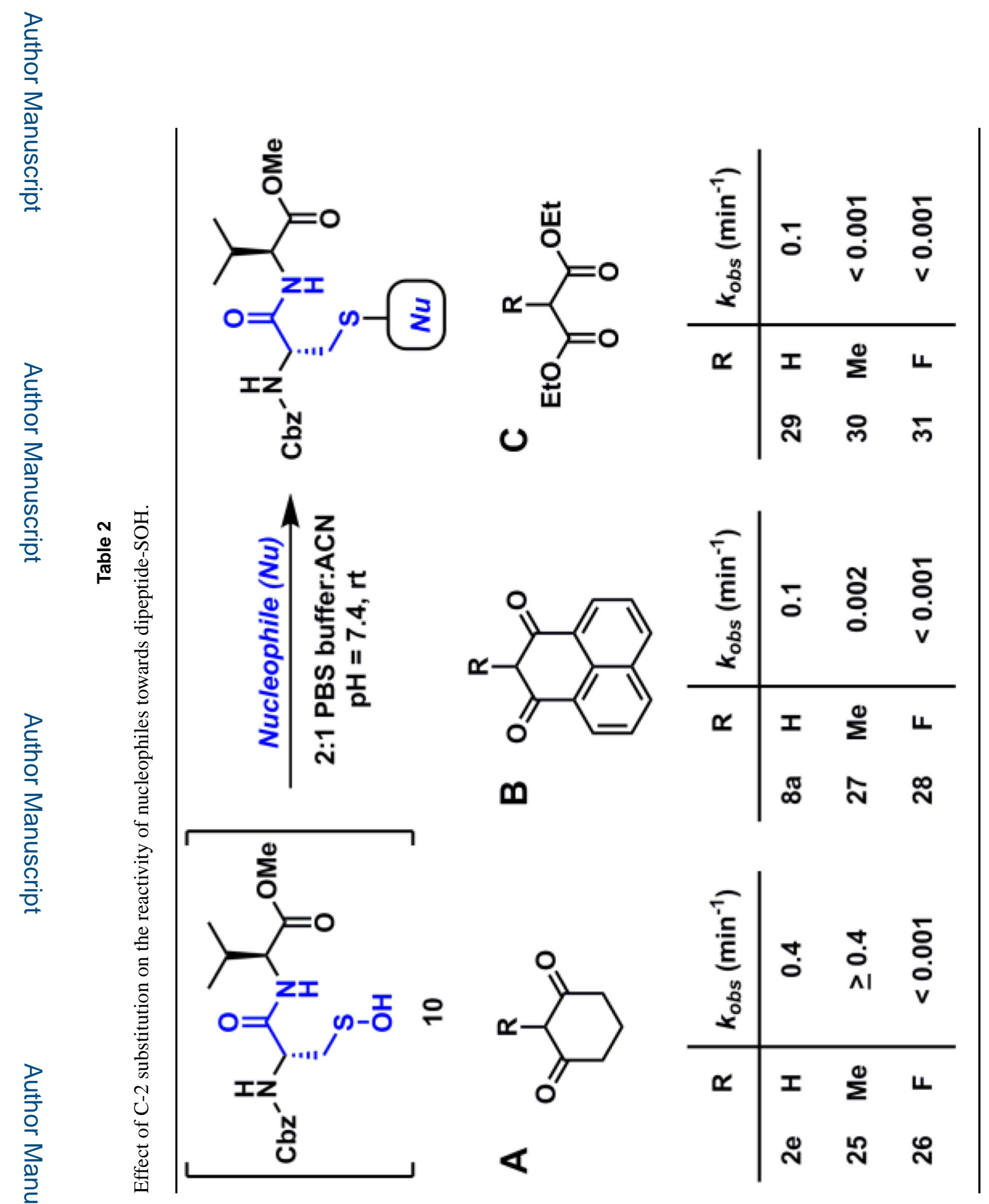

Bioconjug Chem. Author manuscript; available in PMC 2017 May 18. 


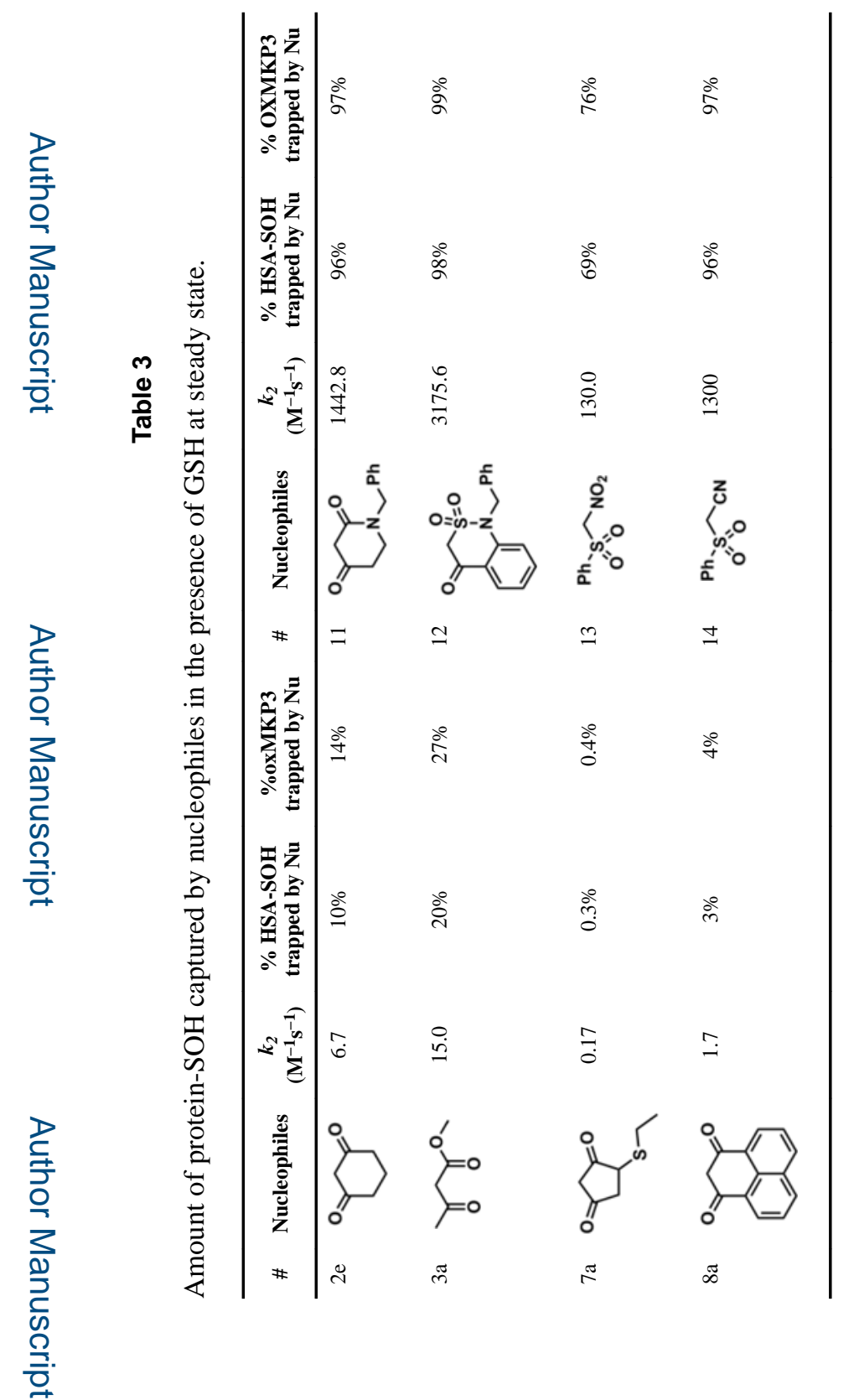

Bioconjug Chem. Author manuscript; available in PMC 2017 May 18. 